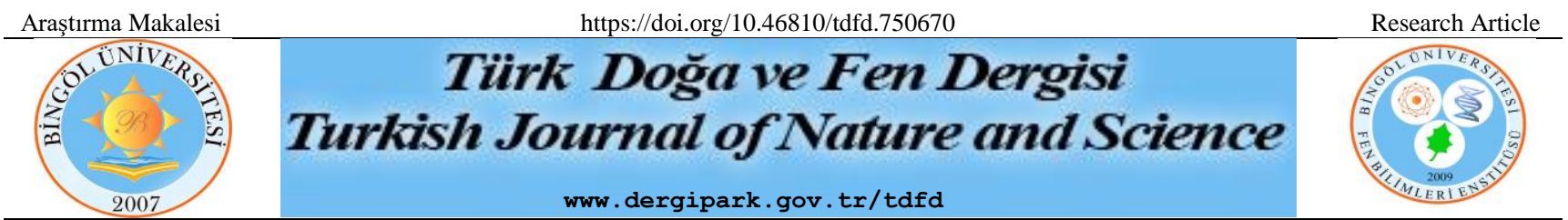

\title{
Dociostaurus (Dociostaurus ) maroccanus Thunberg, 1815 (Acrididae:Orthoptera) Türünün Sürü Oluşturma ve Bitkilere Zarar Durumunun Araştırılması
}

\author{
Mustafa İLÇíN ${ }^{1 *}$, Ali SATAR ${ }^{2}$ \\ ${ }^{1}$ Bingöl Üniversitesi, Ziraat Fakültesi, Bitki Koruma Bölümü, Bingöl, Türkiye \\ ${ }^{2}$ Dicle Üniversitesi, Fen Fakültesi, Biyoloji Bölümü, Diyarbakır, Türkiye \\ Mustafa İLÇİN ORCID No: 0000-0002-2542-9503 \\ Ali SATAR ORCID No: 0000-0002-8008-6291 \\ *Sorumlu yazar: milcin@bingol.edu.tr
}

(Alınış: 10.06.2020, Kabul: 15.10.2020, Online Yayınlanma: 23.10.2020)

\begin{abstract}
Anahtar
Kelimeler

Dociostaurus

(D.)

maroccanus,

Sürü

Oluşturma,

İklimsel

değişimler,

İnsektisit,

Biyolojik

mücadele
\end{abstract}

Öz: Bu çalışmada son yıllarda bitkisel üretime ciddi zararlar veren Orthoptera takımının Acrididae familyasına ait bir tür olan Dociostaurus (Dociostaurus) maroccanus Thunberg, 1815 türünün sürü oluşturma ve bitkisel vejetasyona zarar verme düzeyinin tespit edilmesi ve tanılaması yapılmıştır. Çalışma alanımız olarak Şanlıurfa ili Siverek ilçesine bağlı kırsal alanlar ile Diyarbakır ili Çermik, Çüngüş ilçelerinin kırsal alanlarında toplamda 41 lokalitede bulunan il ve ilçe merkezine bağlı olan köylerdeki bahçe, bostan, ekili alanlar ve tarım arazilerinde tespit edilmiştir. Dociostaurus (Dociostaurus) maroccanus Thunberg, 1815 türünün gregar özellikte olduğu, sürü şeklinde hareket ettiği ve istila ettikleri alanlarda bulunan tarım arazileri, bahçeler, meyve ağaçları, bostanlar, meralar ve diğer kültür bitkilerinde çok ciddi zararlarda bulundukları belirlenmiştir. Dociostaurus (Dociostaurus) maroccanus Thunberg, 1815 türünün artışında iklimsel değişimler, yağıș rejiminin farklılaşması, kuraklık durumlarının meydana gelmesi ve insanların yanlış tarımsal uygulamaları, kimyasal ilaç kullanımı ve yararlı canlı ( Böcek, kuş vb.) tür popülasyonunun azalması en belirleyici etkenler arasında olmuştur. Araştırma gözlemleri çerçevesinde tarımsal arazilerde kullanılan insektisitlerin de zararlı olan tür popülasyonunun artışında etkili olduğu düşünülmektedir. Zararlı olan türün kontrol altına alınabilmesi için üreticilerin en başta önleyici etmenler olarak kültür mücadele, fiziksel-mekaniksel mücadele ve temelde de biyolojik mücadele uygulamalarını gerçekleştirerek türün nimf döneminde ekonomik zarar eşiği altında tutulması son derece etkili olacaktır. Ayrıca yararlı türlerin zararlı popülasyonunu artışının azalmasında kullanılması önerilmektedir.

\section{Dociostaurus (Dociostaurus) maroccanus Thunberg, 1815 (Acrididae:Orthoptera) Species of Swarm and Investigation of Damage to Plants}

Keywords

Dociostaurus

(D.)

maroccanus,

Swarm

Creation,

Climatic

Changes,

Insecticide,

Biological

Control
Abstract: In this study, Dociostaurus (Dociostaurus) maroccanus Thunberg, 1815 a species belonging to Acrididae family of the Orthoptera ordo, which caused serious damage to vegetative production in recent years, was determined and diagnosed. As our study area, it has been determined in rural areas of Şanlıurfa province of Siverek district and in rural areas of Diyarbakır province of Çermik, Çüngüş districts in 41 localities and in the villages connected to the provincial and district centers, gardens, cultivated areas and agricultural lands. Dociostaurus (Dociostaurus) maroccanus Thunberg, 1815 has been found to have serious damage to agricultural lands, gardens, fruit trees, gardens, pastures and other cultivated crops in the areas where 1815 species are gregaric, move in herds and infested. Dociostaurus (Dociostaurus) maroccanus Thunberg, 1815 climatic changes in the increase of species, differentiation of precipitation regime, occurrence of drought conditions, and wrong agricultural practices of humans, use of chemical drugs and decreasing beneficial species (Insect, bird etc.) were among the most determining factors. Within framework of research observations, insecticides used in agricultural lands are also thought to be effective in increasing the harmful species population. In order to control the harmful species, it will be extremely effective for the producers to carry out the cultural damage, physical-mechanical 
and basically biological control practices as the preventive factors and to keep the species under the economic loss threshold during the nymph period. It is also recommended to use the beneficial species in reducing the increase in the pest population.

\section{GíRiş}

Yeryüzünde biyolojik çeşitliliğin büyük bir kısmını böcekler oluşturmuştur. Bu kadar çeşitli olan bu grubun üyeleri Ekvatordan kutuplara, çöllerden ormanlık alanlara, yüksek dağlık alanlardan alçak düzlüklere, bataklıklardan mağaralara, soğuk su kaynaklarından sıcak su kaplıcalarına tarımsal alanlardan evlerimize kadar hemen hemen her türlü ortama dağılmışlardır. Böceklerin bu kadar çeşitli ortama girmeleri ve buralarda yaşamaları uyum yeteneklerinin oldukça güçlü olması sayesinde gerçekleşmiştir [1].

Böcekler, insanların ve diğer canlıların ekolojik ve ekonomik yaşamlarında önemli bir gruptur. Örneğin tarım ve orman ürünleri üzerinde beslenerek direkt ürün kayıplarına neden olabilirler [1].

Türkiye direyi (Latince: Fauna), hayvanlar âleminin Türkiye sınırları içerisinde yaşayan üyelerinin tümüdür. Birçok farklı hayvan türünü barındırması ile dikkat çeker. Anadolu'nun Asya ile Avrupa arasındaki konumu bunda başlıca etkendir. Farklı iklim özelliklerinde coğrafi bölgelere sahip olduğu için, bitki örtüsünün diğer Ortadoğu ülkelerine göre daha zengin (850 cins altında toplanan 9.000 tür bitki) olması ise diğer önemli etkendir. Bu yüzden, farklı iklim ve besin ihtiyacı olan birçok hayvan türü kendisine uygun yaşam alanı bulabilmektedir. Böylece Türkiye'de yalnızca Akdeniz direyinin değil, Orta-Doğu Avrupa, Orta Doğu, Kafkaslar ve Arap Yarımadası direylerinin de tipik türleri bulunmaktadır. Ayrıca Avrupa ülkeleri ile karşılaştırıldığında, çok daha fazla memeli tür barındırır. $\mathrm{Bu}$ da Türkiye direyinin ne tipik Avrupa direyine ne de tipik Orta Doğu direyine sinıflandırılabildiğini gösterir [2].

Orthoptera takımı, 300 milyon yıl öncesine dayanan bir fosiliyle yaşayan böcekler içerisinde en eski takımlardan birisidir. Orthoptera üyeleri orta büyüklükte ve iri arka bacakları sıçrama için iyi gelişmiş böceklerdir. Bileşik gözleri iyi gelişmiş, antenler ince uzun ve çok segmentlidir. Prothoraks geniş, pronotum kalkan şeklinde yanlardan aşağı doğru kıvrılmıştır. Ön kanatlar dar ve derimsi tegminayı oluşturur. Arka kanatlar geniş çok sayıda boyuna ve enine damarlı olup tegmina altında kıvrılırlar. Bu takımda kanatsızlık ve kanat körelmesi yaygındır. Abdomen sekiz veya dokuz görülebilir segmente sahip olup iki ya da üç terminal segment körelmiştir. Serkus tek segmentlidir. Abdominal uzantılardan oldukça farklılaşarak oluşmuş ovopozitör iyi gelişmiştir [1].

Morfolojik ve moleküler bulgulara göre Orthoptera iki monofiletik alttakıma ayrılır. Caelifera (Kısa antenli çekirgeler; gündüz aktif, hızlı hareket eden, şekil itibariyle sivri karasal herbivorlar) ve Ensifera'dır (-
Uzun antenli çekirgeler; genellikle gece aktif, kamuflajlı veya taklitçi, yırtıcı, omnivor veya fitofag) [1].

\section{MATERYAL VE METOT}

Araştırmamıza konu olan türler 2018 yılı nisan-eylül ayları arasında toplanmıştır. Tür örneklerinin toplandığı alanlar, Şanlıurfa ili Siverek ilçesi ve Köyleri; Basyamca Bağlık, Büyüktepe, Beşyamaç, Güldorgun, Narlıkaya, Ortaköy ile Diyarbakır Çermik, Çüngüş ve Karacadağ bölgesi çevresinde bulunan toplamda 41 lokaliteden oluşan bahçeler, bostanlar, meralar, ve tarım arazilerinde kayıt altına alınmıştır. Örnek türlerin toplanmasında genel itibariyle böcek yakalama aracı atrap ve çukur tuzaklardan yararlanılmıştır. Yakalanan Böcek türlerinin muhafazası içinde \% 60 Etil alkol bulunan şişeler sağlanmıştır.

Böcek türünün teşhisi Bei-Bienko and Mistshenko (1951), Ramme (1951), Balamir (1956), Harz (1975), Soltani (1978), Lodos (1983), Willemse (1984, 1985), Naskrecki and Ünal (1995) tarafindan yapılan türteşhisleri ve tür-tayin anahtarları göz önünde bulundurularak tarafımca yapılmıştır $[4,5,6,7,8,9,10,11]$.

\section{BULGULAR}

\section{Cins (Genus): Dociostaurus Fieber, 1853}

Vücut büyüklükleri küçük ya da orta büyüklüktedir. Antenler ipliksi (Filliform) olup baş ile pronotum toplamından daha uzundur. Baş konik yapıda pronotumda kisadır. Verteks lateral kanatsız olup ön sirt ile antenler arasında düz yapıdadır. Tegmina abdomenden kisadır. Alt anal plaka tarafindan ovopozitörün valvleri örtülmüş, açık haldedir. Türler arasındaki karakteristik özellik arka femurun farklı renk özelliklerinde olmasıdır. Araştırma yapılan bölgede yaygın olarak bulunan tür ile temsil edilmektedir [2].

\section{Tür (Species): Dociostaurus (Dociostaurus) maroccanus Thunberg, 1815}

Halk arasında Fas çekirgesi olarak bilinen bu tür en yaygın Orthoptera takımının Acrididae familyasına ait bir tür olarak tespit edilmiştir. Genel özellikleri şu şekildedir: Pronotum Üzerinde ' $\mathrm{X}$ ' İşaretine benzer bir işaret olup orta kısmı silinmiş şekildedir. Ergin olan bireylerin üst kanatları arka femuru geçmektedir. Arka kanatlar renksiz şeffaf olup gövde rengi sarıve grimsi koyu renklerle kaplı, elytra büyük, şeffaftır. Bazen kahverengi benekli olan kanatlarında güçlü damarlanma vardır. Arka ayakları tibia genellikle kırmızı, femurda siyah bantlı ve güçlü yapıdadır. Dişilerin erişkin olanlarının vücut uzunluğu 20-38 mm, erkekler ise 16-28 mm uzunluğundadır. Tegmina 20-30 mm uzunlukta olup $15 \mathrm{~mm}$ enindedir. Tegminada kapak bulunur [2]. 
Zarar Durumu: Beslenme açısından polifag bir tür olup en zararlı Acrididae türlerindendir. Özellikle sürü oluşturacak popülasyonlar meydana getirme yeteneği olduğundan tarım arazilerinde ekonomik zarara yol açarlar. Birçok tahıl bitkisine gerek nimf döneminde gerekse de ergin dönemde yoğun bir şekilde zarar vermektedirler. Güneydoğu Anadolu Bölgesi'nde yaygın olan Buğday tarlaları başta olmak üzere bitkisel vejetasyonunun yoğun olduğu arazilerde büyük zararlar oluşturacak șekilde beslenirler [2].

Tablo 1. Dociostaurus (Dociostaurus) maroccanus Thunberg, 1815 Türünün Zarar Şekilleri

\begin{tabular}{|c|c|c|}
\hline $\begin{array}{l}\text { Bitki } \\
\text { Türü }\end{array}$ & $\begin{array}{c}\text { Zarar Verilen } \\
\text { Organ }\end{array}$ & Zarar Biçimi \\
\hline Buğday & $\begin{array}{l}\text { Tüm yeşil } \\
\text { kısımlar ve } \\
\text { Başaklar }\end{array}$ & $\begin{array}{l}\text { Isırıc1-Çiğneyici ağız yapısı ile } \\
\text { tüm kısımların yenilmesi }\end{array}$ \\
\hline Arpa & $\begin{array}{l}\text { Tüm yeşil } \\
\text { kısımlar ve } \\
\text { Başaklar }\end{array}$ & $\begin{array}{c}\text { I } \\
\text { Isırıcı-Çiğneyici ağız yapısı ile } \\
\text { tüm kısımların yenilmesi }\end{array}$ \\
\hline Mercimek & $\begin{array}{l}\text { Tüm yeşil } \\
\text { kisımlar }\end{array}$ & $\begin{array}{l}\text { Isırıc1-Çiğneyici ağız yapısı ile } \\
\text { tüm kısımların yenilmesi }\end{array}$ \\
\hline Nohut & $\begin{array}{l}\text { Tüm yeşil } \\
\text { kısımlar }\end{array}$ & $\begin{array}{l}\text { Isırıcı-Çiğneyici ağız yapısı ile } \\
\text { tüm kısımların yenilmesi }\end{array}$ \\
\hline Domates & $\begin{array}{c}\text { Yaprak, çiçek ve } \\
\text { meyve }\end{array}$ & $\begin{array}{c}\text { Isırıc1-Çiğneyici ağız yapısı ile } \\
\text { tüm kısımların yenilmesi }\end{array}$ \\
\hline Patlican & $\begin{array}{c}\text { Yaprak, çiçek ve } \\
\text { meyve }\end{array}$ & $\begin{array}{l}\text { Isırıcı-Çiğneyici ağız yapısı ile } \\
\text { tüm kısımların yenilmesi }\end{array}$ \\
\hline Biber & $\begin{array}{c}\text { Yaprak, çiçek ve } \\
\text { meyve }\end{array}$ & $\begin{array}{c}\text { Isırıc1-Çiğneyici ağız yapısı ile } \\
\text { tüm kısımların yenilmesi }\end{array}$ \\
\hline $\begin{array}{l}\text { Meyve } \\
\text { Ağaçları } \\
\text { (Armut, } \\
\text { Elma, } \\
\text { Kayısı, } \\
\text { Kiraz, } \\
\text { Üzüm } \\
\text { vs.) }\end{array}$ & $\begin{array}{c}\text { Yaprak, çiçek ve } \\
\text { meyve }\end{array}$ & $\begin{array}{l}\text { Isırıc1-Çiğneyici ağız yapısı ile } \\
\text { tüm kısımların yenilmesi }\end{array}$ \\
\hline
\end{tabular}

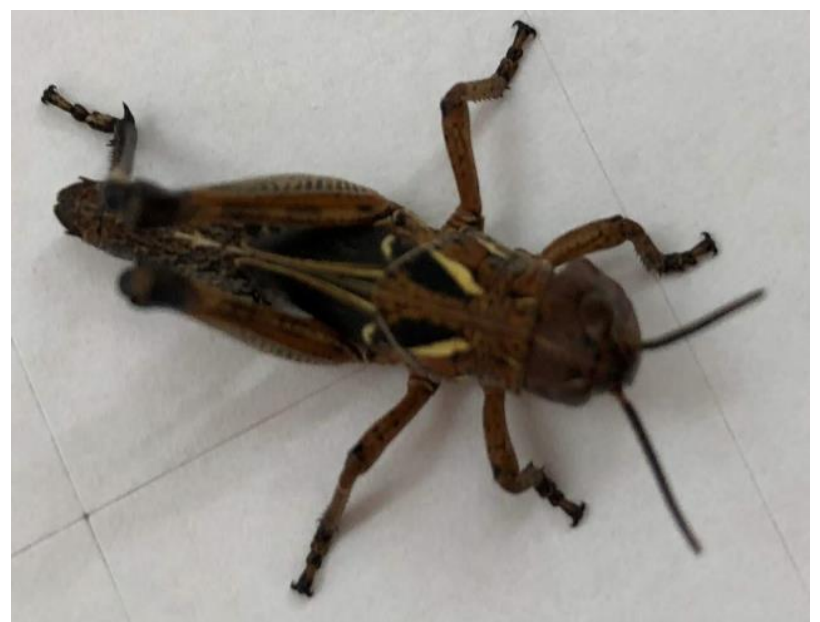

Resim 1. Dociostaurus (Dociostaurus) maroccanus Thunberg, 1815 (Siverek, Mayls, 2018)

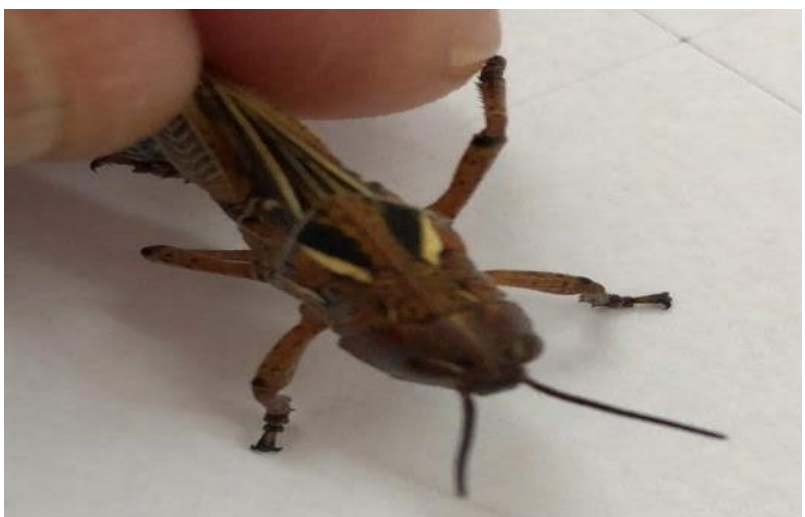

Resim 2. Dociostaurus (Dociostaurus) maroccanus Thunberg, 1815 (Diyarbakır, Haziran, 2018)

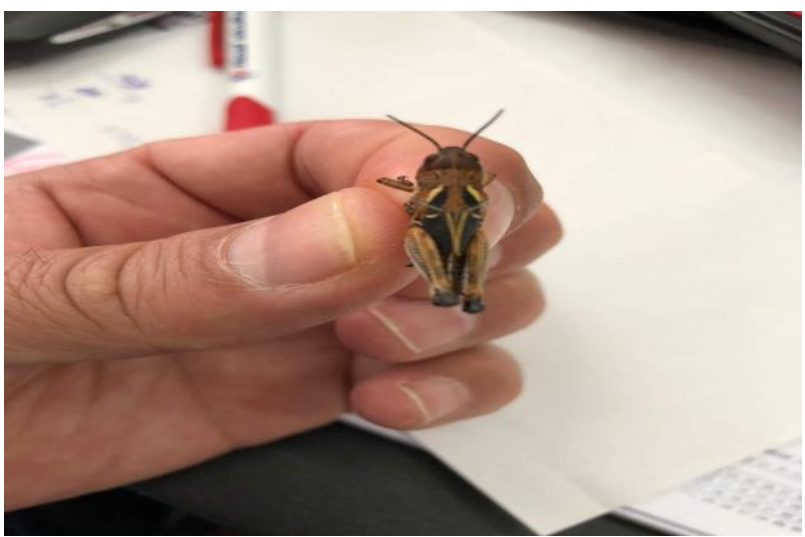

Resim 3. Dociostaurus (Dociostaurus) maroccanus Thunberg, 1815 (Diyarbakır, Haziran, 2018)

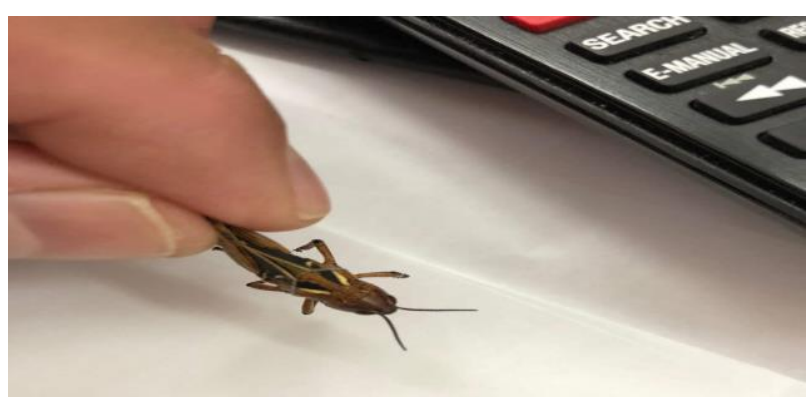

Resim 4. Dociostaurus (Dociostaurus) maroccanus Thunberg, 1815 (Diyarbakır, Haziran, 2018)

\section{SONUÇ}

Araştırmamız sürecinde Orthoptera takımının Acrididae familyasına ait Dociostaurus (Dociostaurus) maroccanus Thunberg, 1815 türünün zararlı bir tür olduğu tespit edilmiş olup Acrididae familyasına ait olan birçok türün de zararlı türler içerdiği, bitkisel vejetasyonu tahrip edip zarar verdikleri belirlenmiştir. Dociostaurus (Dociostaurus) maroccanus Thunberg, 1815 türü polifag beslenme biçimine sahip çok güçlü bir baș ve 1sırıcı-çiğneyici ağız yapısı olan, bu özellikleri nedeniyle pek çok bitkiye zarar vermektedir. Zirai mücadele kapsamında kimyasal mücadelede kullanılan insektisitlere karşı direnç gösterdiği bilinmektedir. Sürü oluşturan ve ulaşabildikleri yerleri istila etme özellikleri 
nedeniyle diğer birçok türden kolaylıkla tanınıp ayrılmaktadır.

Dociostaurus (Dociostaurus) maroccanus Thunberg, 1815 türü özellikle atmosfer değişimlerinden kuraklık başta olmak üzere iklimsel değişimler, yağış rejiminin farklılaşması, sıcaklık ve nem oranlarının değişimi, zararlı tür popülasyonunun artışında en belirleyici abiyotik unsurlar arasındadır. Bununla birlikte zirai mücadele kapsamında kullanılan insektisitlerin yaygınlaşması, zararlı tür popülasyonunun direnç kazanarak artışının yüksek oranlarda gerçekleşmesine yol açmaktadır. Zararlı tür popülasyonunun azalması için en başta kültürel mücadele uygulamaları, fiziksel mücadele, mekaniksel mücadele ve özellikle de biyolojik mücadelenin etkin kullanımı ile olumlu sonuçlar elde edilebileceği düşünülmektedir.

\section{Teșekkür}

$\mathrm{Bu}$ çalışmada desteklerini esirgemeyen ve birlikte çalışmaktan büyük mutluluk duyduğum değerli hocam Prof. Dr. Ali SATAR'a teşekkürlerimi sunarım.

\section{KAYNAKLAR}

[1] Gullan, P. J. Cranston P.S. The Insect An Outline Of Entomology, A. John Wiley\&Sons, Ltd. Publication. 2012.

[2] İlçin, M. Batman İli Ekili alanlarda bulunan Orthoptera: Insecta Faunasının Araştırılması ve Tarım alanlarında Zarar oluşturabilecek Türlerin Belirlenmesi, Doktora Tezi, Fen Bilimleri Enstitüsü Biyoloji Anabilim Dalı, Dicle Üniversitesi, Diyarbakır, 2015.

[3] Demirsoy, A. Erzurum Bölgesi Orthoptera (Insecta) Faunasının Tespiti ve Taksonomik İncelemesi. 1975; 347:39-35.

[4] Demirsoy,A. Türkiye Caelifera (Insecta, Orthoptera) Faunasının Tespiti ve Taksonomik İncelemesi. 1977; 438:8(4), 80-52.

[5] A. R. Akınc1. Çekirge Nimf Yoğunluğunun Tespitinde Uygulanan $m m 2$ 'deki Sayım Yöntemi Yerine Atrapla Sayım Yönteminin Kullanılma Olasılığı Üzerinde Çalışmalar, Bitki Kor. Bült. 1984:24, 1-8.

[6] B. Alkan, Türkiye'de Ziraat Bitkilerinin Genel Zararlıları Üzerinde İncelemeler. Ankara Üniversitesi Ziraat Fakültesi Yayınları.1962:32, 197-125.

[7] H. Ghahari, M. Havaskary, M. Tabari, H. Ostovan, H. Sakenin, A. Satar, An Annotated Catalogue Of Orthoptera(Insecta) And Their Natural Enemics From Iranian Rice Fields And Surrounding Grassland, Linzer biol. Beitr. 2009:30, 639-672.

[8] Satar, A. Özbay, C. On the Orthoptera (Insecta) Fauna of The Karacadağ Mountains and The Dicle Basin (Diyarbakır, Turkey). Boletín de la Sociedad Entomológica Aragoensa (S.E.A.). 2003:32 115120. Available at www.sea-entomologia.org.

[9] Usmani, M. K. et. al. Diversity And Taxonomic
Studies Of Acridoid Pests (Acridoidea: Orthoptera) of Pulses From Vittar Pradesh India. Mun. Ent. Zool. 2012;7(2), 837-846.

[10] Havaskary, M. et al. A Contribution to the ShortHorned Grasshoppers (Orthoptera:Acrididae) From Arasbaran and Vicinity. NW Iran, Mun. Ent. Zool. 2012; 7(2), 970-977.

[11] Badenhausser, I. Amouroux, P. Bretagnolle, V. Estimating Acrididae Densities in Grassland Habitats: A Comparison Between Presence-Absence and Abundance Sampling Designs. Environ. Entomol. 2007; 36(6), 1494-1503. 